\title{
Is vision in schizophrenia characterized by a generalized reduction?
}

\author{
Bernt C. Skottun ${ }^{1 *}$ and John R. Skoyles ${ }^{2}$ \\ ${ }^{1}$ Independent Scholar, Oslo, Norway \\ ${ }^{2}$ Centre for Mathematics and Physics in the Life Sciences and Experimental Biology, University College London, London, UK \\ ${ }^{*}$ Correspondence: berntchrskottun@gmail.com
}

Edited by:

Steven Silverstein, University of Medicine and Dentistry of New Jersey, USA

Reviewed by:

Michael Herzog, École Polytechnique Fédérale de Lausanne, Switzerland

Michael-Paul Schallmo, University of Minnesota, USA

Keywords: schizophrenia, vision, sensitivity, VEPs, magnocellular

\section{A commentary on}

Sensory contributions to impaired emotion processing in schizophrenia

by Butler, P. D., Abeles, I. Y., Weiskopf, N. G., Tambini, A., Jalbrzikowski, M., Legatt, M. E., et al. (2009). Schizophr. Bull. 35, 1095-1107. doi: 10.1093/schbul/sbp109

How the visual capabilities of those with schizophrenia differ from those of individuals without schizophrenia is a topic of active research. Of special interest is the question of whether or not they might have a magnocellular deficiency. It has been concluded that contrast sensitivity in schizophrenic subjects is characterized by a general reduction in sensitivity, and so does not indicate a magnocellular deficiency (Skottun and Skoyles, 2007). Likewise, many of the reported cases of abnormal visual masking linked to schizophrenia can be described by a general reduction (see, e.g., Rassovsky et al., 2004). Also this is hard to reconcile with a magnocellular deficit since, according to the theory, such a deficit would have been expected to cause a reduction that was related specifically to the $\mathrm{U}$-shaped Type-B masking function (Skottun and Skoyles, 2009). These observations prompt the question of whether or not other differences between schizophrenic subjects and controls that have been attributed to magnocellular deficiencies can also be accounted by a general reduction in sensitivity or response.

Differences between schizophrenic subjects and nonschizophrenic controls attributed to magnocellular deficiencies have been found using visually evoked potentials (VEP). Butler et al. (2009) obtained VEP data for schizophrenic subjects and controls under two conditions. One condition aimed at predominantly stimulating the magnocellular system, the other the parvocellular system. Butler et al. (2009) found statistically significant reduction in the responses from the schizophrenic subjects, relative to those of controls, under the condition favoring the magnocellular system but not under the parvocellular condition. The authors interpreted this as evidence for a magnocellular deficiency linked to schizophrenia. The present report examines the possibility that these results could reflect instead a general response reduction.

The data of Butler et al. (2009) have been re-plotted in Figure 1. The open and filled symbols give the results for the schizophrenic subjects and controls, respectively, while panels $\mathrm{A}$ and $\mathrm{B}$ give the data obtained under the magnoand parvocellular conditions. A general response reduction was modeled by a simple linear scaling of the response from the control group. The scaling factor was determined by the best fit to the data of the schizophrenic subjects by calculating the smallest sum of squared deviations. Analyses of both magno- and parvocellular data conditions were included, giving a single scaling value of 0.756 . (The scaling factors for the magno- and parvocellular data sets computed separately were 0.737 and 0.797 , respectively). The scaled data are indicated by the dashed lines in Figure 1. Even though the data for the

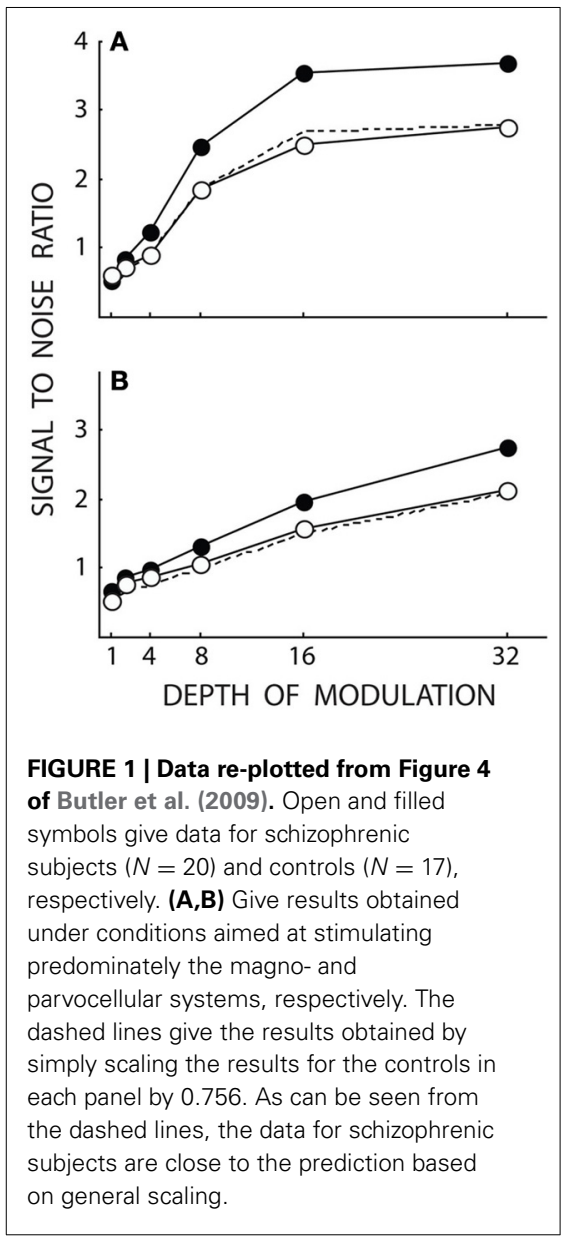

schizophrenic subjects in the magnocellular condition in some instances are slightly below the dashed line and the data in the parvocellular condition in some cases are slightly above the dashed line, the overall finding is that the scaled data give close fits to the data for the schizophrenic subjects for both conditions. This suggests that 
Butler et al.'s (2009) data for schizophrenic subjects in both the magnocellular and the parvocellular conditions are consistent with scaling by the same factor. This is consistent with a general reduction in the response rather than a difference (as suggested by Butler et al., 2009) between the magnocellular and parvocellular systems. No reason therefore exists to account for these data with a deficiency linked specifically to the magnocellular system.

One explanation for the differences between controls and schizophrenic subjects being significant in the magnocellular condition but not in the parvocellular one could be that the response differences were larger in the magnocellular condition. The fact that the responses were larger in this condition would have made the difference between the groups (as a result of scaling by a constant) larger under this condition, and so more likely to result in a statistically significant difference.

Further, it is an invalid inference to conclude that a magnocellular deficiency exists solely based on the finding that a magnocellular condition gives statistically significant differences whereas a parvocellular condition does not. To do so would require making an interpretation of the non-significant data-but a statistically non-significant result does not allow any conclusions to be inferred (Gill, 1999).
The finding that the difference is statistically significant under the magnocellular condition and not under the parvocellular condition, moreover, is not itself strictly pertinent. What might have been somewhat more relevant would have been if the difference between the data obtained under the two conditions were statistically significant. (It should in this connection be kept in mind that the difference between a statistically significant result and a nonsignificant result need not itself be statistically significant. Gelman and Stern, 2006). However, it is not clear that even this would have solved the problem since it may be possible for a single factor to have effects that are different under different conditions (as shown in Figure 1). The difference between these effects may, or may not, be statistically significant.

\section{SUMMARY}

We have demonstrated that the VEP data of Butler et al. (2009) are very well described by a general response reduction. This argues that abnormal visual performance in schizophrenia reflects a general reduction in sensitivity or response amplitude rather than a magnocellular deficiency.

\section{REFERENCES}

Butler, P. D., Abeles, I. Y., Weiskopf, N. G., Tambini, A., Jalbrzikowski, M., Legatt, M. E., et al. (2009). Sensory contributions to impaired emotion processing in schizophrenia. Schizophr. Bull. 35, 1095-1107. doi: 10.1093/schbul/sbp109

Gelman, A., and Stern, H. (2006). The difference between "significant" and "not significant" is not itself statistically significant. Am. Stat. 60, 328-331. doi: 10.1198/000313006X152649

Gill, J. (1999). The insignificance of null hypothesis significance testing. Polit. Res. Q. 52, 647-674. doi: 10.1177/106591299905200309

Rassovsky, Y., Green, M. F., Nuechterlein, K. H., and Breitmeyer, B. (2004). Paracontrast and metacontrast in schizophrenia: clarifying the mechanism for visual masking deficits. Schizophr. Res. 71, 485. doi: 10.1016/j.schres.2004.02.018

Skottun, B. C., and Skoyles, J. R. (2007). Contrast sensitivity and magnocellular functioning in schizophrenia. Vision Res. 47, 2923-2933. doi: 10.1016/j.visres.2007.07.016

Skottun, B. C., and Skoyles, J. R. (2009). Are masking abnormalities in schizophrenia specific to type-B masking? World J. Biol. Psychiatry 10, 798-808. doi: 10.1080/15622970903051944

Received: 27 November 2013; accepted: 15 December 2013; published online: 27 December 2013.

Citation: Skottun BC and Skoyles JR (2013) Is vision in schizophrenia characterized by a generalized reduction? Front. Psychol. 4:999. doi: 10.3389/fpsyg.2013.00999

This article was submitted to Psychopathology, a section of the journal Frontiers in Psychology.

Copyright (C) 2013 Skottun and Skoyles. This is an open-access article distributed under the terms of the Creative Commons Attribution License (CC BY). The use, distribution or reproduction in other forums is permitted, provided the original author(s) or licensor are credited and that the original publication in this journal is cited, in accordance with accepted academic practice. No use, distribution or reproduction is permitted which does not comply with these terms. 